CLINICAL STUDY

\title{
Long-term results of treatment in patients with ACTH-secreting pituitary macroadenomas
}

\author{
S Cannavò, B Almoto, C Dall'Asta ${ }^{1}$, S Corsello ${ }^{2}, \mathrm{R}$ M Lovicu ${ }^{2}$, E De Menis ${ }^{3}$, F Trimarchi and B Ambrosi ${ }^{1}$ \\ Department of Medicine and Pharmacology, University of Messina, Italy, ${ }^{1}$ Institute of Endocrine Sciences, University of Milan, Italy, \\ ${ }^{2}$ Institute of Endocrinology, Catholic University, Rome, Italy and ${ }^{3}$ Medical Division Io, Regional Hospital of Treviso, Italy \\ (Correspondence should be addressed to S Cannavò, Unit of Endocrinology-Department of Medicine and Pharmacology, Pad. H, $4^{\circ}$ piano, \\ Azienda Ospedaliera Universitaria 'Policlinico G. Martino', Via Consolare Valeria, 1, I-98125, Messina, Italy; Email: endocrinologi@hotmail.com)
}

\begin{abstract}
Objective: Since Cushing's disease due to large pituitary tumors is rare, we evaluated biochemical characteristics at entry and the results of first surgical approach and of adjuvant therapeutic strategies during a long-term follow-up period.

Design: We studied 26 patients (nine male, 17 female; $42.5 \pm 12.7$ years, mean \pm S.E.) with ACTHsecreting pituitary macroadenoma (tumor diameter: $11-40 \mathrm{~mm}$ ).

Methods: At entry, plasma ACTH, serum cortisol and 24-h urinary free cortisol (UFC) levels were measured in all patients, a high-dose dexamethasone (dexa) suppression test was evaluated in 22 cases and a corticotrophin releasing hormone (CRH) test in 20 cases. Patients were re-evaluated after operation and, when not cured, they underwent second surgery, radiotherapy and/or ketoconazole treatment. The follow-up period was $78 \pm 10$ months.

Results: Before surgery, dexa decreased ACTH (>50\% of baseline) in only 14/22 patients. The CRHstimulated ACTH/cortisol response was normal in six patients, impaired in six patients and exaggerated in eight patients. After operation eight patients were cured, nine had normalized cortisol levels and nine were not cured. Pre-surgery, mean ACTH values were significantly higher in the not cured patients than in those normalized $(P<0.05)$ and cured $(P<0.01)$; the ACTH response to CRH was impaired in only six patients of the not cured group. The tumour diameter was significantly less in cured patients $(P<0.02)$ and in normalized patients $(P<0.05)$ than in the not cured ones. Magnetic resonance imaging (MRI) showed invasion of the cavernous sinus in 2/9 normalized, and in 6/9 not cured patients. After surgery, ACTH, cortisol and UFC were significantly lower than at entry in cured and in normalized patients, but not in not cured patients. In the cured group, the disease recurred in one patient who was unsuccessfully treated with ketoconazole. In the normalized group, a relapse occurred in eight patients: radiotherapy and ketoconazole induced cortisol normalization in one case, hypoadrenalism in one case and were ineffective in another one, while five patients were lost at follow-up. In the not cured group, eight patients underwent second surgery, radiotherapy and/or ketoconazole, while one patient was lost at follow-up. These therapies induced cortisol normalization in two patients and hypoadrenalism in one.

Conclusions: (i) A sub-set of patients with ACTH-secreting pituitary macroadenoma showed low sensitivity to high doses of dexamethasone and to CRH, (ii) pituitary surgery cured Cushing's disease in a minority of patients, (iii) high baseline ACTH levels, impaired ACTH response to CRH, increased tumor size or invasion of the cavernous sinus were unfavourable prognostic factors for surgical therapy, and (iv) second surgery, radiotherapy and/or ketaconazole cured or normalized hypercortisolism in half of the patients with recurrence or not cured.
\end{abstract}

European Journal of Endocrinology 149 195-200

\section{Introduction}

Cushing's disease is a rare condition observed in about $8-10 \%$ of patients with pituitary tumor. In the majority of cases, adrenocorticotrophin (ACTH)-secreting pituitary adenomas are small, intrasellar and less than $10 \mathrm{~mm}$ in diameter, while macroadenomas occur in $4-10 \%$ of the patients (1). ACTH-secreting macroadenomas can grow rapidly and become so large as to induce symptoms due to mass effect, before causing endocrine consequences. It was postulated that the prolonged period preceding the onset of symptoms can be due to the fact that plasma ACTH levels are relatively low in many cases (2). Moreover, it has been reported that Cushing's disease due to macroadenoma is characterized by different biochemical features compared with microadenomas (3). In fact, ACTH suppressibility induced by high-dose dexamethasone administration, 
usually observed in patients with ACTH-secreting pituitary microadenomas, is completely lost in many cases with large tumours (3). In another study (4), it was suggested that cavernous sinus invasion and tumor size are the only predictors of residual disease after surgery and that macroadenomas are more refractory to conventional treatments than are microadenomas. However, the correlation between tumor size and surgical outcome was not confirmed recently by Chee et al. (5).

The aim of this study was to evaluate the hormonal characteristics before treatment and the outcome after the first surgical approach and after adjuvant therapeutic strategies during a long-term follow-up period in a series of 26 patients with ACTH-secreting pituitary macroadenoma.

\section{Materials and methods}

\section{Patients}

We studied 26 patients with ACTH-secreting pituitary macroadenoma ( 9 males and 17 females, age $42.5 \pm 12.7$, range $19-66$ years) referred to the Endocrine Units of Messina, Milano, Roma and Treviso hospitals. At entry, basal and dynamic endocrine and neuroradiological evaluations were performed in all cases. All patients underwent pituitary surgery (21 by the transsphenoidal and 5 by the pterional route) and were then re-evaluated. Patients not cured underwent second surgery, radiotherapy (by external conventional method or by gamma-knife technique) and/or medical treatment (ketoconazole, up to $800 \mathrm{mg}$ daily p.o.). The follow-up period was $78 \pm 10$ months (range $25-$ 190 months).

Patients were classified as 'cured', 'normalized' or 'not cured' on the basis of hormonal and neuroradiological findings after surgery and after subsequent therapies, at the last control visit. They were judged 'cured' when no tumour remnants were found at the last magnetic resonance (MR) imaging and transient or persistent hypoadrenalism followed the therapeutic approach, 'normalized' when the treatment was followed by the normalization of adrenal function but not by hypoadrenalism, and 'not cured' when clinical features, hormonal and neuroradiological findings were substantially unchanged.

\section{Endocrine evaluation}

At entry, plasma ACTH, serum cortisol and 24-h urinary free cortisol (UFC) levels were measured in all patients in basal conditions and after low-dose oral dexamethasone administration (1 mg overnight). A high-dose oral dexamethasone suppression test was performed in 22 patients ( $8 \mathrm{mg}$ daily for 2 days (13 patients) or $8 \mathrm{mg}$ overnight (9 patients)). A loperamide test (16 mg p.o.) was performed in 9 out of 26 patients and cortisol levels were measured at 0, 120, 180 and $240 \mathrm{~min}$. The responsiveness to corticotrophin releasing hormone (human CRH $100 \mu \mathrm{g}$ i.v. or ovine CRH $1 \mu \mathrm{g} / \mathrm{kg}$ i.v.) was tested in 20 patients by measuring ACTH and cortisol levels at $-30,0,15,30,45$ and $60 \mathrm{~min}$.

Responsiveness to a low-dose dexamethasone test or to a loperamide test was defined as 'normal' when cortisol levels fell under $40 \mathrm{ng} / \mathrm{ml}$. Plasma ACTH and serum cortisol decreases after high-dose dexamethasone administration were defined as 'appropriate' (i.e. indicative of pituitary-dependent Cushing's disease) if both values fell more than $50 \%$ and as 'impaired' if they fell less than $50 \%$ of baseline. Responsiveness to the CRH test was defined as 'normal' if ACTH and cortisol levels increased between $35 \%$ and $50 \%$ of baseline values, 'impaired' if the increases in ACTH or cortisol values were below $35 \%$ and 'exaggerated' if the increase in one or both hormones was over $50 \%$ of baseline levels.

All patients were re-evaluated after first surgery and after adjuvant therapies, by measuring baseline ACTH, cortisol and UFC levels. Serum cortisol inhibition after low-dose dexamethasone or after loperamide administration was determined in 11 and 10 cases respectively. After surgery, plasma ACTH and/or serum cortisol responsiveness to a $\mathrm{CRH}$ test was evaluated in 17 cases.

Plasma ACTH levels were measured in duplicate by commercially available immunoradiometric assay (IRMA) methods. Serum cortisol levels and UFC excretion were measured in duplicate by commercially available competitive enzyme immunoassay or radioimmunoassay. The intra- and interassay coefficients of variation for all assays were $<5 \%$ and $<10 \%$ respectively.

\section{Imaging}

Tumor size was evaluated by high resolution MR imaging, and T1-weighted $3 \mathrm{~mm}$ thick sagittal and coronal spin-echo images were obtained. The maximal craniocaudal height and width of the tumour were measured on T1-weighted coronal and sagittal planes after gadolinium DPTA i.v. injection. The mean diameter of pituitary adenoma was $17.8 \pm 0.7 \mathrm{~mm}$ (range $11-40$ ).

\section{Statistical analysis}

Data are expressed as means \pm s.E. Statistical analysis was performed by Student's $t$-test for paired or unpaired data and by $\chi^{2}$ test.

\section{Results}

\section{Baseline endocrine evaluation}

At baseline, mean plasma ACTH and serum cortisol levels were $128 \pm 15 \mathrm{pg} / \mathrm{ml}$ and $253 \pm 16 \mathrm{ng} / \mathrm{ml}$ respectively. Mean UFC excretion was $402 \pm 83 \mu \mathrm{g} / 24 \mathrm{~h}$. 
Low-dose dexamethasone or loperamide administration did not adequately inhibit cortisol levels in any of the patients.

High-dose dexamethasone administration decreased plasma ACTH, serum cortisol and/or UFC levels in 14 patients (ACTH: $-76 \pm 13 \%$; cortisol: $-77 \pm 4 \%$; UFC: $-88 \pm 7 \%$ ), but not in another 8 cases (ACTH: $23 \pm 26 \%$; cortisol: $-8 \pm 11 \%$; UFC: $-32 \%$ and $+387 \%$, evaluated in two cases).

The CRH test induced normal ACTH and cortisol responses in six patients, while the response was impaired in six patients and exaggerated in eight patients.

An impairment of the hypothalamic-pituitary function was found in 15 out of 26 patients. Isolated central hypothyroidism (as proven by low baseline serum free thyroxine, free triiodothyronine and thyrotrophin (TSH) levels and abnormal thyrotrophin releasing hormone-stimulated TSH responsiveness) was detected in seven cases, hypogonadotrophic hypogonadism (as assessed by impaired luteinizing hormone releasing hormone-stimulated follicle stimulating hormone and luteinizing hormone responsiveness) in two cases, hypothyroidism and hypogonadism in three cases, hypothyroidism and growth hormone $(\mathrm{GH})$ deficiency (as proven by low serum insulin-like growth factor-I levels and impaired $\mathrm{GH}$ responsiveness to hypoglycemia) in two cases and hypothyroidism, hypogonadism and GH deficiency in another patient.
Mean serum prolactin (PRL) levels were $22.8 \pm 5.1 \mathrm{ng} / \mathrm{ml}$, and elevated PRL values were found in seven cases (range $27-130 \mathrm{ng} / \mathrm{ml}$ ).

\section{Surgical outcome}

Baseline neuroradiological findings, surgical outcome and final outcome of patients are shown in Table 1.

After adenomectomy, immunohistochemistry was performed and was positive for ACTH in all cases. Moreover, a positivity for PRL was found in patient no. 4 with high PRL levels $(130 \mathrm{ng} / \mathrm{ml})$.

Following first surgery, mean ACTH, cortisol and UFC levels were significantly lower than at baseline $(\mathrm{ACTH}$ $68 \pm 15 \mathrm{pg} / \mathrm{ml}, P<0.0002$; cortisol $176 \pm 21 \mathrm{ng} / \mathrm{ml}$, $P<0.01$; UFC $123 \pm 35 \mu \mathrm{g} / 24 \mathrm{~h}, \quad P<0.002)$. Eight patients were considered cured (after the transsphenoidal approach), nine normalized (eight cases after the transsphenoidal and one after the pterional approach) and nine not cured (five after the transsphenoidal and four after the pterional approach).

The evaluation of pre-surgical ACTH values in each group showed that mean ACTH levels were significantly higher in the not cured patients (190.6 $32.8 \mathrm{pg} / \mathrm{ml})$ than in the cured $(86.7 \pm 19.3 \mathrm{pg} / \mathrm{ml}$, $P<0.01)$ and in the normalized patients $(114.6 \pm$ $11.9 \mathrm{pg} / \mathrm{ml}, P<0.05)$, while serum cortisol or UFC levels were not significantly different in the three groups (cured group: cortisol $256.7 \pm 29.5 \mathrm{ng} / \mathrm{ml}$, UFC

Table 1 Age, sex, neuroradiological findings (tumor size, expressed in $\mathrm{mm}$, and cavernous sinus invasion, if present) and outcome, after first surgery and at the end of the observation period, in 26 patients with ACTH-secreting pituitary macroadenomas.

\begin{tabular}{|c|c|c|c|c|c|c|}
\hline Case number & $\begin{array}{c}\text { Age } \\
\text { (years) }\end{array}$ & Sex & $\begin{array}{c}\text { Tumor } \\
\text { size }(\mathrm{mm})\end{array}$ & $\begin{array}{c}\text { Cavernous } \\
\text { sinus invasion }\end{array}$ & $\begin{array}{l}\text { Outcome after } \\
\text { first surgery }\end{array}$ & Final outcome \\
\hline 1 & 40 & $\mathrm{~F}$ & 15 & + & Not cured & Died \\
\hline 2 & 46 & $\mathrm{~F}$ & 15 & - & Cured & Recurred \\
\hline 3 & 53 & $\mathrm{~F}$ & 18 & + & Normalized & Lost \\
\hline 4 & 41 & $\mathrm{M}$ & 16 & + & Not cured & Cured \\
\hline 5 & 28 & $\mathrm{~F}$ & 15 & - & Cured & Cured \\
\hline 6 & 22 & $\mathrm{~F}$ & 15 & - & Not cured & Not cured \\
\hline 7 & 58 & $\mathrm{~F}$ & 12 & - & Cured & Cured \\
\hline 8 & 33 & $\mathrm{~F}$ & 13 & + & Normalized & Lost \\
\hline 9 & 60 & $M$ & 14 & - & Cured & Cured \\
\hline 10 & 66 & $\mathrm{~F}$ & 11 & + & Not cured & Lost \\
\hline 11 & 34 & $\mathrm{~F}$ & 12 & - & Normalized & Not cured \\
\hline 12 & 64 & $M$ & 32 & + & Not cured & Died \\
\hline 13 & 51 & $\mathrm{M}$ & 12 & - & Cured & Cured \\
\hline 14 & 36 & $\mathrm{M}$ & 15 & - & Normalized & Lost \\
\hline 15 & 40 & $\mathrm{~F}$ & 11 & - & Cured & Cured \\
\hline 16 & 33 & $M$ & 12 & - & Cured & Cured \\
\hline 17 & 45 & $\mathrm{~F}$ & 15 & - & Cured & Cured \\
\hline 18 & 45 & $M$ & 25 & - & Normalized & Normalized \\
\hline 19 & 52 & $\mathrm{~F}$ & 18 & - & Normalized & Normalized \\
\hline 20 & 36 & $M$ & 25 & + & Not cured & Not cured \\
\hline 21 & 45 & $\mathrm{~F}$ & 12 & - & Normalized & Lost \\
\hline 22 & 56 & $\mathrm{~F}$ & 18 & - & Not cured & Normalized \\
\hline 23 & 19 & $\mathrm{M}$ & 40 & + & Not cured & Normalized \\
\hline 24 & 38 & $\mathrm{~F}$ & 30 & - & Not cured & Not cured \\
\hline 25 & 30 & $\mathrm{~F}$ & 15 & - & Normalized & Lost \\
\hline 26 & 32 & $\mathrm{~F}$ & 18 & - & Normalized & Cured \\
\hline
\end{tabular}


$442.3 \pm 138.1 \mu \mathrm{g} / 24 \mathrm{~h}$; normalized group: cortisol $293.2 \pm 32.5 \mathrm{ng} / \mathrm{ml}$, UFC $542.1 \pm 224.3 \mu \mathrm{g} / 24 \mathrm{~h}$; not cured group: cortisol $225.9 \pm 21.3 \mathrm{ng} / \mathrm{ml}$, UFC $268.0 \pm 45.1 \mu \mathrm{g} / 24 \mathrm{~h}$ ). An impaired ACTH responsiveness to $\mathrm{CRH}$ was observed in only six not cured patients. At imaging, the tumour size was significantly larger in not cured $(23.4 \pm 3.5 \mathrm{~mm})$ than in cured $(13.0 \pm 0.6 \mathrm{~mm}, \quad P<0.02)$ and in normalized patients $(16.0 \pm 1.5 \mathrm{~mm}, P<0.05)$; invasion of the cavernous sinus was detected in only two out of nine normalized patients and in six out of nine not cured ones $\left(\chi^{2}\right.$ 9.3, $\left.P<0.01\right)$.

After surgery, mean ACTH, cortisol and UFC levels were significantly lower than at entry in the cured (ACTH: $13.4 \pm 4.3$ vs $86.7 \pm 19.3 \mathrm{pg} / \mathrm{ml}, \quad P<0.005$; cortisol: $18.6 \pm 3.8$ vs $256.7 \pm 29.5 \mathrm{ng} / \mathrm{ml}, P<0.0005$; UFC: $37.1 \pm 12.0$ vs $442.3 \pm 138.1 \mu \mathrm{g} / 24 \mathrm{~h}, P<0.05)$ and in the normalized group (ACTH $42.8 \pm 3.8$ vs $114.6 \pm 11.9 \mathrm{pg} / \mathrm{ml}, P<0.001$; cortisol $178.5 \pm 16.9$ vs $293.2 \pm 32.5 \mathrm{ng} / \mathrm{ml}, P<0.01$; UFC $97.4 \pm 16.0$ vs $542.1 \pm 224.3 \mu \mathrm{g} / 24 \mathrm{~h}, \quad P<0.05)$, but were superimposable in the not cured patients (ACTH 153.6士 29.1 vs $190.6 \pm 32.8 \mathrm{pg} / \mathrm{ml}$; cortisol $257.6 \pm 37.2$ vs $225.9 \pm 21.3 \mathrm{ng} / \mathrm{ml}$; UFC $270.5 \pm 107.7 \quad$ vs $268.0 \pm 45.1 \mu \mathrm{g} / 24 \mathrm{~h}$ ) (Fig. 1). The ACTH and cortisol responsiveness to $\mathrm{CRH}$ was evaluated in 17 patients (six cured, six normalized, and five not cured). In the cured group, the response was impaired in three cases (patients 7,13 and 17) and exaggerated in another three (patients 9, 15 and 16). In the normalized group, the response was impaired in two (patients 18 and 19), normal in one (patient 21) and exaggerated in three cases (patients 8, 11 and 14). In the not cured group, the response was impaired in four cases (patients 6,10 , 12 and 23) and exaggerated in another one (patient 22). Post-surgical ACTH responsiveness to CRH did not predict the outcome in operated patients $\left(\chi^{2} 0.7\right.$, $P=$ not significant).

In the cured group, the follow-up period was $52 \pm 15$ months. After surgery, three patients (patients 5, 7, 13) needed life-long substitution with cortisone acetate, while in the other five cases replacement treatment was discontinued after 4-12 months (patients 2, 9, $15,16,17)$. A relapse occurred only in patient no. 2 who was unsuccessfully treated with ketoconazole.

In the normalized group, the follow-up period was $41 \pm 12$ months. Cushing's disease recurred in eight out of nine patients, 2-69 months after surgery. The other patient was still normalized after 24 months (patient 19). Three of the relapsed patients underwent conventional radiotherapy (patients 18, 26) or $\gamma$-knife radiotherapy and ketoconazole treatment (patient 11). These adjuvant treatments induced normalization of pituitary-adrenal function in one case (patient 18) and hypoadrenalism in another patient (no. 26), but were ineffective in patient no. 11. The other five patients (nos 3, 8, 14, 21, 25) were lost at follow-up after the relapse.
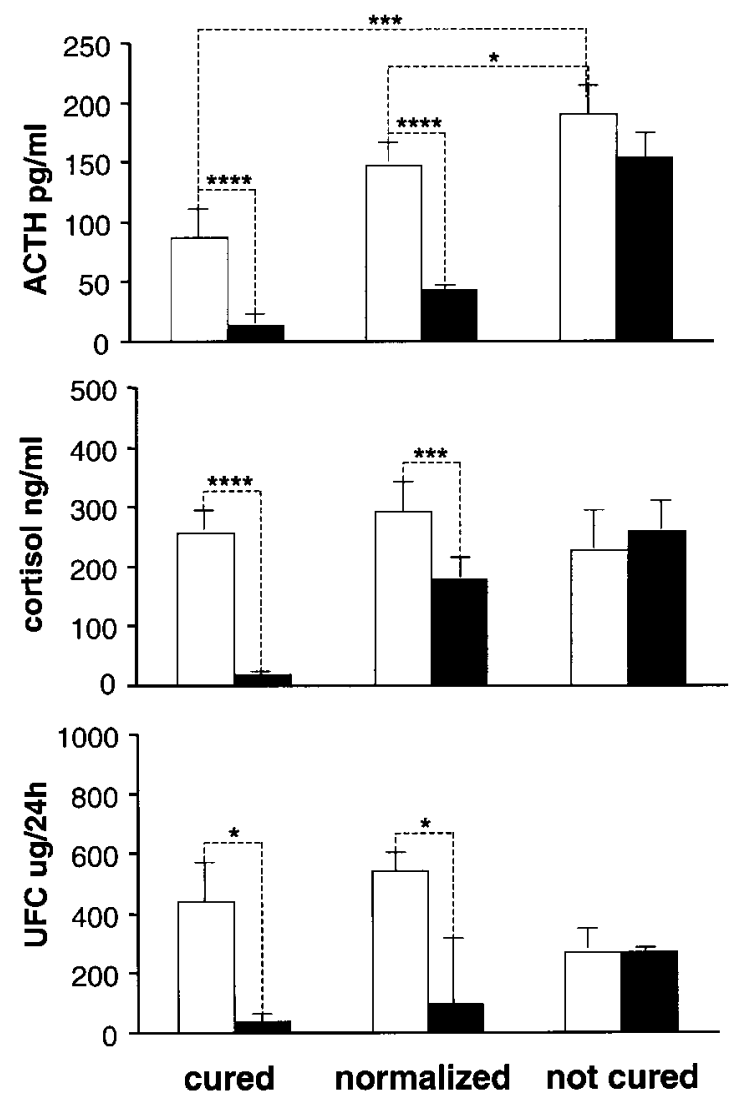

Figure 1 Plasma ACTH, serum cortisol and urinary free cortisol (UFC) levels at entry (baseline, open columns) and after first surgery (solid columns) in cured, normalized and not cured patients. ${ }^{\star} P<0.05,{ }^{\star \star \star} P<0.01,{ }^{* \star \star \star} P<0.005$.

In the not cured group, the follow-up period was $57 \pm 21$ months. Eight patients underwent second surgery (patients 4, 6, 12, 22, 23, 24), conventional (patients 1, 4, 20, 22, 23 and 24) or $\gamma$-knife (patient 6 ) radiotherapy, and ketoconazole treatment following radiotherapy (patients 1, 6, 20). Adjuvant therapies induced hypoadrenalism in one case (patient 4), normalization of cortisol levels in two patients (nos 22, 23), but were ineffective in the other three (patients $6,20,24)$. In this group, the last MR imaging showed the disappearance of pituitary adenoma in four patients (nos 4, 20, 22, 23). Two patients died, patient no. 1 of unknown causes and patient 12 due to surgical consequences. Patient no. 10 was lost at follow-up after surgery.

\section{Discussion}

This study demonstrates that the effectiveness of the surgical approach and the long-term outcome after adjuvant therapies are unsatisfactory in the majority of patients with ACTH-secreting pituitary macroadenomas. Pituitary surgery, by the transsphenoidal or the 
transcranial approach, cured the disease in eight out of 26 patients and normalized hypercortisolism in another $35 \%$ of cases, while in the remaining patients ACTH, cortisol and UFC levels did not decrease significantly. Moreover, Cushing's disease recurred in eight out of nine patients in the normalized group, while relapse occurred in only one case in the cured group. The identification of reliable predictors for long-term remission in patients with ACTH-secreting pituitary macroadenomas is a critical finding of this study, because it is often necessary to decide whether radiotherapy is required or not. Our study confirms that the achievement of post-surgical hypoadrenalism is a marker of successful outcome in patients with macroadenomas, while the normalization of adrenal function is frequently followed by relapse of the disease. In patients with Cushing's disease due to small tumours, the relapse rate is $6-11 \%$ in cured patients and $15-$ $26 \%$ in normalized ones $(6-8)$. However, it is evident that the invasiveness of the pituitary adenoma, i.e. the tumor size and the invasion of the cavernous sinus, was also correlated with an unfavourable outcome after both the first surgery and the adjuvant treatments. The diameter of the adenoma was significantly larger in not cured patients than in normalized and in cured ones and cavernous sinus invasion was detected in $22 \%$ of normalized and in $67 \%$ of not cured cases, but in none of the cured patients.

Another good predictable index for surgical outcome seems to be baseline ACTH levels, as they were significantly lower in cured patients than in normalized and in not cured ones. It is noteworthy that only ACTH levels were positively correlated with tumor size, while cortisol and UFC levels were not. We can speculate that the bioactivity of ACTH secreted by huge tumors was greatly reduced and this could explain the paucity of signs and symptoms in some patients with ACTH-secreting macroadenoma, as reported by Ikeda et al. (2). On the contrary, in our patients with ACTH-secreting pituitary microadenomas the surgical outcome was not correlated with either baseline plasma ACTH levels or tumor size (data not shown).

In our experience, an impaired ACTH responsiveness to $\mathrm{CRH}$ before surgery could be considered a predictable index of recurrence, as it was found only in patients not cured by surgery, i.e. in 30\% of overall patients. Also Bochicchio et al. (8) reported that patients with normal or exaggerated pre-surgical ACTH/cortisol responses to $\mathrm{CRH}$ had a minor risk of surgical failure in comparison with not responders. Pecori Giraldi et al. (9) speculated that endogenous cortisol negatively modulates $\mathrm{CRH}$-stimulated corticotroph secretion in some CRH-unresponsive patients with Cushing's disease, but we cannot confirm this suggestion because in our patients cortisol levels were not very elevated and in many cases plasma ACTH values were not reduced by high-dose dexamethasone administration. Katznelson et al. (1) and Ikeda et al. (2) showed that the set-point for ACTH suppressibility by dexamethasone can be altered and high doses of drug are sometimes unable to decrease ACTH and cortisol levels in patients with ACTH-secreting macroadenomas. In our study, $36 \%$ of patients showed an inadequate ACTH inhibition after high doses of dexamethasone. We could speculate that reduced ACTH bioactivity, impaired sensitivity to $\mathrm{CRH}$, insensitivity to dexamethasone, together with growth and invasiveness of the tumor, could be an index of a low degree of differentiation in the adenomatous corticotroph cells and in this regard they could explain a poor prognosis.

Adjuvant therapies, radiotherapy and/or ketoconazole, induced the remission of hypercortisolism in only half of the ten treated patients. In 1998, Blevins et al. (4) reported that surgery was ineffective in 33\% of their patients with ACTH-secreting macroadenomas, while radiotherapy normalized UFC levels in 57\% of cases and the drugs, ketoconazole or bromocriptine, were more effective when employed after radiotherapy. In our study, radiotherapy was effective in $56 \%$ of the patients, while the following medical treatment was unsuccessful in the other $44 \%$ of cases.

As far as the other pituitary trophins are concerned, hypopituitarism was found in $58 \%$ of the patients: isolated hypothyroidism or hypogonadism was detected in $47 \%$ and in $13 \%$ of them, while other pituitary deficiencies were found in one or two cases. The occurrence of hypopituitarism in patients harbouring huge adenomas is well known (10), but, to our knowledge, there are no data about its prevalence in patients with ACTH-secreting macroadenoma. Blevins et al. (4) reported a low prevalence of permanent hypogonadism and hypothyroidism after transsphenoidal surgery. However, it is unclear whether pituitary deficiency is due to compression or destruction of the pituitary gland by the tumor or to the effects of hypercortisolism on pituitary function. In our experience, the remission of hypercortisolism did not induce the recruitment of pituitary deficiency in any of the five cured or normalized hypopituitaric patients. In accordance with previous reports (11), hyperprolactinaemia was found in about a quarter of our patients, but baseline PRL values were over $100 \mathrm{ng} / \mathrm{ml}$ and immunohistochemical evaluation stained positively for PRL only in one case. The co-secretion of PRL and ACTH by the same adenomatous cells is a rare event, as recently reported by Barausse et al. (12) and Barbetta et at. (13). In the other cases, hyperprolactinaemia is probably due to stalk compression or to the influence of paracrine regulation factors, i.e. galanine, secreted by adenomatous cells (14).

In conclusion, our study confirms that a sub-set of patients with ACTH-secreting pituitary macroadenomas shows low sensitivity to high doses of dexamethasone and to $\mathrm{CRH}$ administration. Pituitary surgery induces the remission of Cushing's disease in a minority of patients. High baseline ACTH levels, impaired ACTH 
response to $\mathrm{CRH}$, increased tumor size or invasion of the cavernous sinus are unfavorable prognostic factors for surgical therapy. Moreover, repeat surgery, radiotherapy and/or ketaconazole treatment cure or normalize hypercortisolism in half of recurred or not cured patients.

\section{References}

1 Katznelson L, Bogan JS, Trob JR, Schoenfeld DA, Hedley-Whyte ET, Hsu DW et al. Biochemical assessment of Cushing's disease in patients with corticotroph macroadenomas. Journal of Clinical Endocrinology and Metabolism 199883 1619-1623.

2 Ikeda N, Yoshimoto T, Ogawa Y, Mizoi K \& Murakami G. Clinicopathological study of Cushing's disease with large pituitary adenoma. Clinical Endocrinology 199746 669-679.

3 Klibanski A \& Zervas NT. Diagnosis and management of hormone secreting pituitary adenomas. New England Journal of Medicine $199121822-823$.

4 Blevins LS, Christy JH, Khajavi M \& Tindall GT. Outcomes of therapy for Cushing's disease due to adrenocorticotropinsecreting pituitary macroadenomas. Journal of Clinical Endocrinology and Metabolism 199883 63-67.

5 Chee GH, Mathias DB, James RA \& Kendall-Taylor P. Transsphenoidal pituitary surgery in Cushing's disease: can we predict outcome? Clinical Endocrinology 200154 617-626.

6 Barbetta L, Dall'Asta C, Tomei G, Locatelli M, Giovanelli M \& Ambrosi B. Assessment of cure and recurrence after pituitary surgery for Cushing's disease. Acta Neurochirurgica 2001143 $477-482$

7 Invitti C, Pecori Giraldi FP, de Martin M \& Cavagnini F. Diagnosis and management of Cushing's syndrome: results of an Italian multicentre study. Study Group of the Italian Society of Endocrinology on the Pathophysiology of the
Hypothalamic-Pituitary-Adrenal Axis. Journal of Clinical Endocrinology and Metabolism $1999 \mathbf{8 4} 440-448$.

8 Bochicchio D, Losa M, Buchfelder M \& the European Cushing's Disease Survey Study Group. Factors influencing the immediate and a late outcome of Cushing's disease treated by transsphenoidal surgery: a retrospective study by the European Cushing's Disease Survey Group. Journal of Clinical Endocrinology and Metabolism $1995803114-3120$.

9 Pecori Giraldi F, Invitti C, Cavagnini F \& Study Group of the Italian Society of Endocrinology on the Pathophysiology of the Hypothalamic-Pituitary-Adrenal Axis. The corticotropin-releasing hormone test in the diagnosis of ACTH-dependent Cushing's syndrome: a reappraisal. Clinical Endocrinology $2001 \mathbf{5 4}$ 601-607.

10 Webb S, Rigla M, Wagner A, Oliver B \& Bartumeus F. Recovery of hypopituitarism after neurosurgical treatment of pituitary adenomas. Journal of Clinical Endocrinology and Metabolism 1999 $843696-3700$.

11 Yamaji T, Ishibashi M, Teramoto A \& Fukushima T. Hyperprolactinemia in Cushing's disease and Nelson's syndrome. Journal of Clinical Endocrinology and Metabolism 198458 790-795.

12 Barausse M, Attanasio R, Dallabonzana D, Oppizzi G, Veronese S, Lasio $\mathrm{G}$ et al. From macroprolactinoma to concomitant ACTH-PRL hypersecretion with Cushing's disease. Journal of Endocrinological Investigation 200023 107-111.

13 Barbetta L, Dall'Asta C \& Ambrosi B. Hyperprolactinemia preceding Cushing's disease. Journal of Endocrinological Investigation 200023 491-492.

14 Gheri RG, Boddi W, Ammannati F, Olivotto J, Nozzoli C, Franchi A et al. Two-step development of a pituitary adenoma: from hyperprolactinemic syndrome to Cushing's disease. Journal of Endocrinological Investigation 199720 240-244.

Received 10 January 2003

Accepted 10 June 2003 